\title{
MODERNIZATION OF THE IRKUTSK INCOHERENT SCATTER RADAR
}

\author{
D.S. Kushnarev \\ Institute of Solar-Terrestrial Physics SB RAS, \\ Irkutsk,Russia,ds_k@iszf.irk.ru \\ V.P. Lebedev \\ Institute of Solar-Terrestrial Physics SB RAS, \\ Irkutsk,Russia,lebedev@iszf.irk.ru

\section{V.V. Khakhinov} \\ Institute of Solar-Terrestrial Physics SB RAS, \\ Irkutsk,Russia, khakhin@iszf.irk.ru
}

\author{
S.E. Evstifeev \\ Institute of Solar-Terrestrial Physics SB RAS, \\ Irkutsk, Russia,e-serg@iszf.irk.ru \\ V.E. Zarudnev \\ Institute of Solar-Terrestrial Physics SB RAS, \\ Irkutsk, Russia,zarudnev@iszf.irk.ru
}

\begin{abstract}
We present the results of modernization of the Irkutsk Incoherent Scatter Radar's control and acquisition system. The modernization was carried out using results of space experiments Plasma-Progress and Radar-Progress involving Progress cargo spacecraft. The modernization has improved the accuracy of radar measurements of low-orbit spacecraft. For example, with a signal-to-noise ratio equal to10, the accuracy of
\end{abstract}

range and angle measurements is $100-300 \mathrm{~m}$ and $1-5$ arc min.

Keywords: radar, Irkutsk Incoherent Scatter Radar, Plasma-Progress and Radar-Progress space experiments.

\section{INTRODUCTION}

One of the main tasks of space experiments (SE) Plasma-Progress (2007-2009) [http://www.energia.ru/ rus/iss//researches/geophis-13. html; Lebedev et al., 2008; Potekhin et al., 2009] and Radar-Progress (20102015) [http://knts.tsniimash.ru//ru/site/Experiment_q. aspx?idE=183; Khakhinov et al., 2013] was to analyze the effect of exhaust jets from liquid propellant engines on the radio image of a low-orbit spacecraft by comparing reflection characteristics of Progress cargo spacecraft having operative and inoperative engines. A distinctive feature of the SE is a weak ionospheric effect of exhaust jets (the amount of exhaust products from 2 to $11 \mathrm{~kg}$ ).

Reflection characteristics of Progress cargo spacecraft (CS) were measured with the Irkutsk Incoherent Scatter Radar (IISR) [Zherebtsov et al., 2002; Lebedev et al., 2013]. During the SE, IISR's digital control and acquisition system (DCAS) was upgraded in several stages to improve methods for acquiring and processing the coordinate and reflection characteristics of the spacecraft.

The SE sessions were held during the Progress CS autonomous flight after undocking from the ISS. When the Progress CS was within the field of view of the radar, the onboard liquid propellant engines started. From session to session, the direction of exhaust jet, the direction of solar illumination of exhaust plume, and the direction of jet velocity relative to the geomagnetic field vector varied. Simultaneously with parameters of the rocket exhaust-induced ionospheric disturbances, we recorded background undisturbed values of ionospheric parameters along the sounding path.

\section{THE IRKUTSK INCOHERENT SCATTER RADAR}

The Irkutsk Incoherent Scatter Radar is a unique scientific instrument in Russia based on the equipment of the radar station Dnepr. IISR is a monostatic pulse radar with frequency scanning. The range of the radar's operating frequencies is $154-162 \mathrm{MHz}$; the peak power, achieved with two transmitters, is $2.8 \mathrm{MW}$; the sounding pulse duration is from 70 to $900 \mu \mathrm{s}$; the pulse repetition rate is $24.4 \mathrm{~Hz}$; the antenna gain is $\sim 35 \mathrm{~dB}$. The main difference between IISR and other radars of this type lies in the design features of its antenna.

\section{STAGES OF MODERNIZATION OF THE IRKUTSK INCOHERENT SCATTER RADAR}

\subsection{Features of DCAS modernization until} 2008

The progress in diagnostic capabilities of IISR between 2003 and 2008 was facilitated by the radical modernization of the entire system of control, reception, and acquisition devices and signal processing facilities in order to make full use of the radar potential and design features of its antenna. The main task of the modernization was to provide the following radar capabilities:

1) measuring parameters of ionospheric plasma simultaneously in several directions to study its spatially inhomogeneous structure;

2) simultaneous measurements without amplitude distortions of power signals from SC or coherent echo against weak incoherent scatter signals;

3) controlling the shape of the antenna pattern (AP) and making interferometric measurements;

4) automatically detecting the presence of coherent signals on the radar scan, providing the possibility of making an automatic decision to change the operating mode;

5) increasing spatial resolution and expanding the 
vertical range of ionospheric measurements by using optimum sounding signals and eliminating signals reflected from local objects from the radar scan;

6) making soft copies of the total volume of raw sounding data to ensure selection of a secondary processing method adequate for changing tasks and environmental conditions;

7) processing a large ionosphere and satellite sounding dataset.

Accomplishing the tasks at hand required the development of a new DCAS, which includes

- a multichannel receiver;

- a digital system for synchronizing and generating operating frequencies;

- a system for automatic transmitter phasing;

- a system for recording the shape of a transmitted pulse;

- a high-speed device for acquiring signals and controlling the radar;

- a distributed computer system for secondary processing of sounding data.

This DCAS was employed in all experiments conducted with IISR in 2007-2012 [Potekhin et al., 2008].

\subsection{Features of DCAS modernization for the Radar-Progress SE}

With the beginning of the first Radar-Progress SE sessions, as well as to solve current problems of monitoring the spacecraft, new requirements to this DCAS were formulated:

- the accuracy of matching to the global navigation/timing systems should be no worse than $1 \mu \mathrm{s}$;

- digital receivers with a reception bandwidth of up to $1 \mathrm{MHz}$, a dynamic range of $60 \mathrm{~dB}$, a linear and highly stable phase-frequency characteristic of the receiving path in the required reception bandwidth, a programmable gain;
- the capability of generating complex sounding signals and their sequences.

To solve these problems in IISR's DCAS, we had to

- integrate a high-precision GPS receiver into the control system;

- apply modern chips to synthesizers of radio frequencies, which enable us to specify durations, frequencies, and types of manipulation of sounding signals (AM, FM, LFM);

- modify the control unit to operate the GPS receiver and new synthesizers;

- use modern digital receivers to expand the dynamic range and ensure the linearity of PFC of the receiving path;

- eliminate "redundant" analog units such as multipliers by 8 and the receiving unit at the second intermediate frequency;

- install a system of online processing of received signals, reflected from the spacecraft, into IISR's computing system.

In the SE sessions in 2011, a new Digital Down Converter (DDC) and a new timing system began to be installed. The digital receiver is a separate system for acquiring radio signals, which is based on up-to-date components and allows us to digitize, demodulate, process, and store received signals in a given frequency band. This system utilized a single-purpose, computer board Insys ADP64Z2APCI and a submodule of digital acquisition ADMDDC416x100M with basic parameters listed in Table 1.

The DDC submodule was connected to the outputs of the receiving unit and acquired a signal at the first intermediate frequency of $18.75 \mathrm{MHz}$, thus allowing us to discard some analog units and second intermediate frequency. At the same time, the software control of the submodule's parameters enabled us to change IISR's operating modes in a timely and flexible manner.

Table 1

Digital receiver parameters

\begin{tabular}{|l|c|}
\hline \multicolumn{1}{|c|}{ Parameter } & Value \\
\hline Number of ADC channels & 4 \\
\hline Number of DDC channels & 16 bits \\
\hline ADC capacity & Texas Instruments GC5016 \\
\hline DDC chip type & $2-140 \mathrm{MHz}$ \\
\hline Frequency range of input signals & $105 \mathrm{MHz}$ \\
\hline ADC maximum sampling rate & $85 \mathrm{~dB}$ \\
\hline Spurious Free Dynamic Range (SFDR) for $F=21.4 \mathrm{MHz}$ & $71 \mathrm{~dB}$ \\
\hline Signal/noise ratio (SNR) for $F=21.4 \mathrm{MHz}$ & $50 \mathrm{Ohm}$ \\
\hline Input impedance & $\pm 0.5 \mathrm{~V}$ \\
\hline Input range & \\
\hline
\end{tabular}




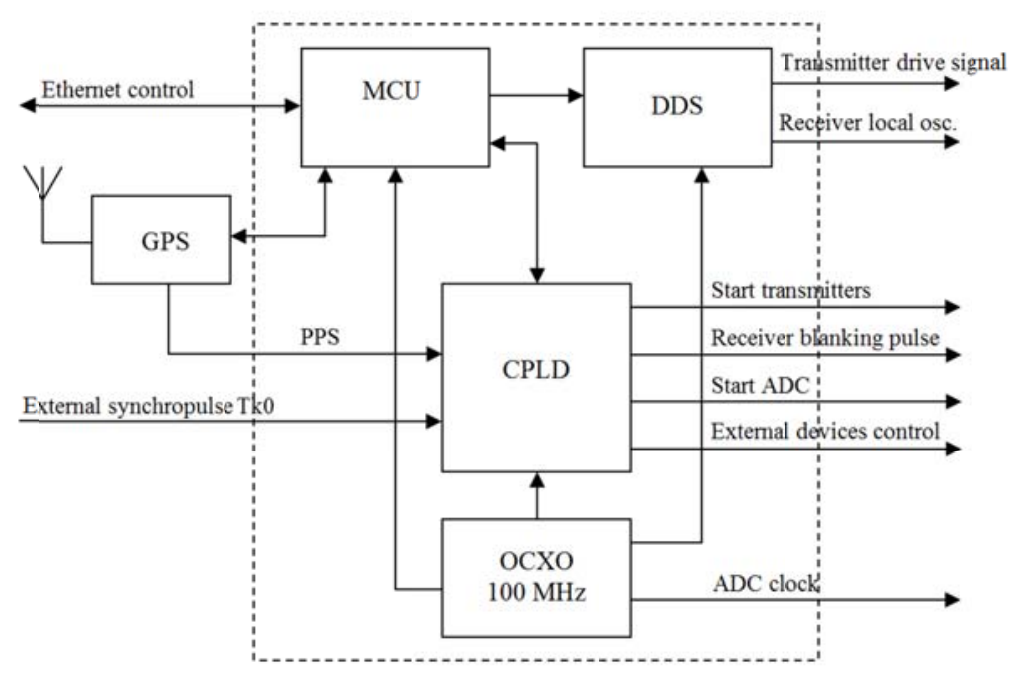

Figure 1. Flow chart of a new system for synchronizing and forming IISR operating frequencies

The SE observations of different types exploited different reception bandwidths (from $25 \mathrm{kHz}$ to $1 \mathrm{MHz}$ ) and different gains.

This system through the DDC submodule was connected in parallel with the regular acquisition system of DCAS and was used in 2012-2014 only to monitor the spacecraft.

In 2014, the next stage of IISR modernization occurred. A new system for synchronizing and generating operating frequencies was devised and implemented. It has the following capabilities:

- generating control synchrosignals for all IISR units (start/stop signals of transmitters, switching tubes, receivers);

- the source of all signals is a single reference oscillator;

- forming operating frequencies for transmitters, local oscillators of receivers, and other IISR systems;

- controlling the transmitter phasing system;

- interacting with the control computer via the Ethernet interface.

Figure 1 shows a flow chart of a new control system for IISR. Its kernel is a microcontroller unit (MCU) based on a high-speed ARM processor. The unit is de- signed to configure and control the Direct Digital Synthesizers (DDS), Complex Programmable Logic Device (CPLD), to connect with a GPS receiver, and interact with the control computer. Immediately after power-up of this unit, all subsystems are configured to default operating parameters. Then, the connection is established to the control software of the host computer and settings needed for a particular experiment are downloaded. As a channel of control and connection with the control computer, the Ethernet controller and User Datagram Protocol (UDP) are used.

The source of a single reference frequency for all the radar systems was a temperature-stabilized quartz oscillator of $100 \mathrm{MHz}(\mathrm{OCXO} \mathrm{M} 33005)$ with a relative instability of $1.5 \cdot 10^{-9} \mathrm{~s}$. The same oscillator is used as a clock frequency source for digital IISR receivers.

The subsystem for generating operating frequencies is implemented using two AD9958 synthesizers produced by Analog Devices; these DDS are programmed by MCU and facilitate generation of complicated modulated (FM, LFM) sounding signals in the operating band of the radar $154-162 \mathrm{MHz}$ for various experiments. These synthesizers form heterodyne frequencies for IISR's receivers.

Table 2

Stages of IISR modernization

\begin{tabular}{|c|c|c|c|c|}
\hline Date & Type of transmitted signals & $\begin{array}{l}\text { Duration } \\
\text { of radar } \\
\text { signal, } \mu \mathrm{s}\end{array}$ & $\begin{array}{c}\text { Receiver } \\
\text { bandwidth, } \\
\mathrm{kHz}\end{array}$ & Stages of IISR modernization \\
\hline 2007, September & 43-element phase-shift signal & \multirow{3}{*}{860} & \multirow{3}{*}{100} & \multirow{8}{*}{$\begin{array}{l}\text { 1) analog receiver, two interme- } \\
\text { diate frequencies; } \\
\text { 2) ADC: } 1 \mathrm{MHz} \text { clock fre- } \\
\text { quency, } 70 \mathrm{~dB} \text { dynamic range; } \\
\text { 3) operating frequency syn- } \\
\text { thesizer STEL1276, } 20 \\
\text { MHz operating range; } \\
\text { 4) frequency multiplier unit } \\
x 8 \text {; } \\
\text { 5) } \pm 0.5 \mathrm{~s} \text { software timing } \\
\text { accuracy }\end{array}$} \\
\hline 2008, February & & & & \\
\hline $\begin{array}{l}2008, \text { September, } \\
1-3\end{array}$ & $\begin{array}{l}\text { sequence of rectangular and } 43 \text {-element } \\
\text { phase-shift signals }\end{array}$ & & & \\
\hline 2008, September, & \multirow{5}{*}{$\begin{array}{l}\text { sequence of rectangular and } 13 \text {-element } \\
\text { phase-shift signals }\end{array}$} & \multirow{5}{*}{858} & 50 & \\
\hline 2009, February & & & & \\
\hline 2009, September & & & 50 & \\
\hline 2010, April & & & 600 & \\
\hline $\begin{array}{l}2010, \\
\text { August-September }\end{array}$ & & & 25 & \\
\hline
\end{tabular}




\begin{tabular}{|c|c|c|c|c|}
\hline 2011, April & & & $\begin{array}{c}25 \\
500\end{array}$ & \\
\hline 2011, August & $\begin{array}{l}\text { sequence of two 13-element phase-shift } \\
\text { signals (at different operating frequencies) } \\
\text { transmitted in one sounding pulse }\end{array}$ & $442+442$ & & $\begin{array}{l}\text { 6) receiver: analog-digital, } \\
\text { one intermediate frequency; } \\
\text { 7) ADC+DDC: } 100 \mathrm{MHz} \\
\text { clock frequency, } 85 \mathrm{~dB} \mathrm{dy-} \\
\text { namic range; }\end{array}$ \\
\hline $\begin{array}{l}\text { 2012, April } \\
\text { 2012, August } \\
\text { 2013, April } \\
\text { 2013, June }\end{array}$ & $\begin{array}{l}\text { sequence of two flat signals in one sound- } \\
\text { ing pulse; in the next pulse, a chirp signal is } \\
\text { transmitted, } \\
498.891 \mathrm{MHz} / \mathrm{s} \text { frequency tuning rate }\end{array}$ & $\begin{array}{c}442+442 \\
902\end{array}$ & 1000 & $\begin{array}{l}\text { 8) timing: GPS, } 10^{-6} \mathrm{~s} \text { accu- } \\
\text { racy }\end{array}$ \\
\hline $\begin{array}{l}\text { 2014, April } \\
\text { 2014, July }\end{array}$ & $\begin{array}{l}\text { sequence of two flat signals in one } \\
\text { sounding pulse; in the next pulse, a chirp } \\
\text { signal is transmitted; the tuning rate is } \\
407.452 \mathrm{MHz} / \mathrm{s}\end{array}$ & (LFM) & & $\begin{array}{l}\text { 9) operating frequency synthe- } \\
\text { sizer: AD9958; } 40 \mathrm{MHz} \text { op- } \\
\text { erating frequency range; } \\
\text { 10) frequency multiplier unit: } \\
\text { x4; }\end{array}$ \\
\hline
\end{tabular}

The basic logic of control signal generation is implemented in CPLD. Input signals for it are represented by a clock frequency of $100 \mathrm{MHz}$ from the OCXO oscillator and an external synchropulse Tk0 with a repetition rate of $24.4 \mathrm{~Hz}$. All other service signals for different IISR units are formed from these two signals. The CPLD matrix has internal control registers accessible to $\mathrm{MCU}$, thus facilitating flexible generation of sequences of synchrosignals depending on experimental conditions, for example, a quick shift of the position of the "Start ADC" signal on the time scan of transmission-reception cycles in each sounding pulse to gain information from different vertical ranges. The synchronizing system provides a precise phase matching of all signals to the OCXO reference oscillator.

The synchronizing subsystem with a unified precise time scale is based on a high-stable GPS receiver Trimble Thunderbolt. Connection with this receiver is also established through MCU. Via the serial interface, it gets current date/time, and due to the high-precision pulse per second (PPS) it syncs all the transmission-reception cycles up to $10^{-6} \mathrm{~s}$. This makes it possible to substantially increase the synchrony of all observation modes in such a complicated experiment as Radar-Progress.

\section{IISR OPERATING MODES}

The Radar-Progress SE involves two main operating modes of IISR:

- ionospheric observation mode;

- spacecraft monitoring mode.

The ionospheric observation mode serves to detect a signal scattered from ionospheric plasma in a vertical range $150-1200 \mathrm{~km}$. Signals are emitted by two phased transmitters with a pulse power of $1.2 \mathrm{MW}$ each. DCAS generates two probing pulses with durations of 700 and $200 \mu \mathrm{s}$, one of which is filled with a 5-element Barker code with a spatial resolution of $6 \mathrm{~km}$. The digital receiver and the acquisition system record separate time scans of a received signal in four independent channels with bandwidths of 125 and $250 \mathrm{kHz}$ respectively. Received signals from narrowband channels are used to obtain ion and electron temperatures and plasma drift velocities [Potekhin et al., 2008; Shcherbakov et al., 2015]; signals from broadband channels serve as the basis for constructing vertical electron density profiles of ionospheric plasma [Alsatkin et al., 2015].

The spacecraft monitoring mode involves scanning a specific sector in the IISR AP in order to detect and track an object. In this sector, Progress CS onboard engines are switched on and off. DCAS turns on this mode by the time the CS enters the IISR scanning sector minus DT seconds and turns it off when the CS exits the scanning sector plus DT seconds; DT ranges from 15 to $30 \mathrm{sec}-$ onds. The scanning area and the number of operating frequencies $N$ (AP azimuths) involved in scanning depend on the geometry of the experiment, i.e. on the area of intersection of the scanning sector and the CS ephemeris. All parameters (time, frequency, waveforms, receiving interval length, ADC and DDC parameters) are calculated in advance and downloaded using configuration files to the DCAS control software.

During all the SEs, simultaneously with IISR upgrading, we tried sounding signals of different types. Table 2 lists stages and types of signals used in a given period. In April 2012, an alternating mode comprising signals of two types was adopted for spacecraft monitoring: two flat (unmodulated) signals and one signal with chirp filling, lasting for $442+442$ and 902 microseconds respectively. Rectangular signals allows us to determine the range, radial velocity, and, rather roughly, angles. The chirp signal facilitates a high-precision identification of the antenna azimuth, as well as the range and the antenna elevation angle. The joint use of signals of the two types provides the most complete and accurate set of flight path information.

\section{RESULTS OF THE MODERNIZATION}

After being modernized, IISR's DCAS features the following capabilities.

The programmable logic allows us to flexibly change the operating modes of the radar systems according to the tasks set in the experiments, without creating any new or modified hardware units. 

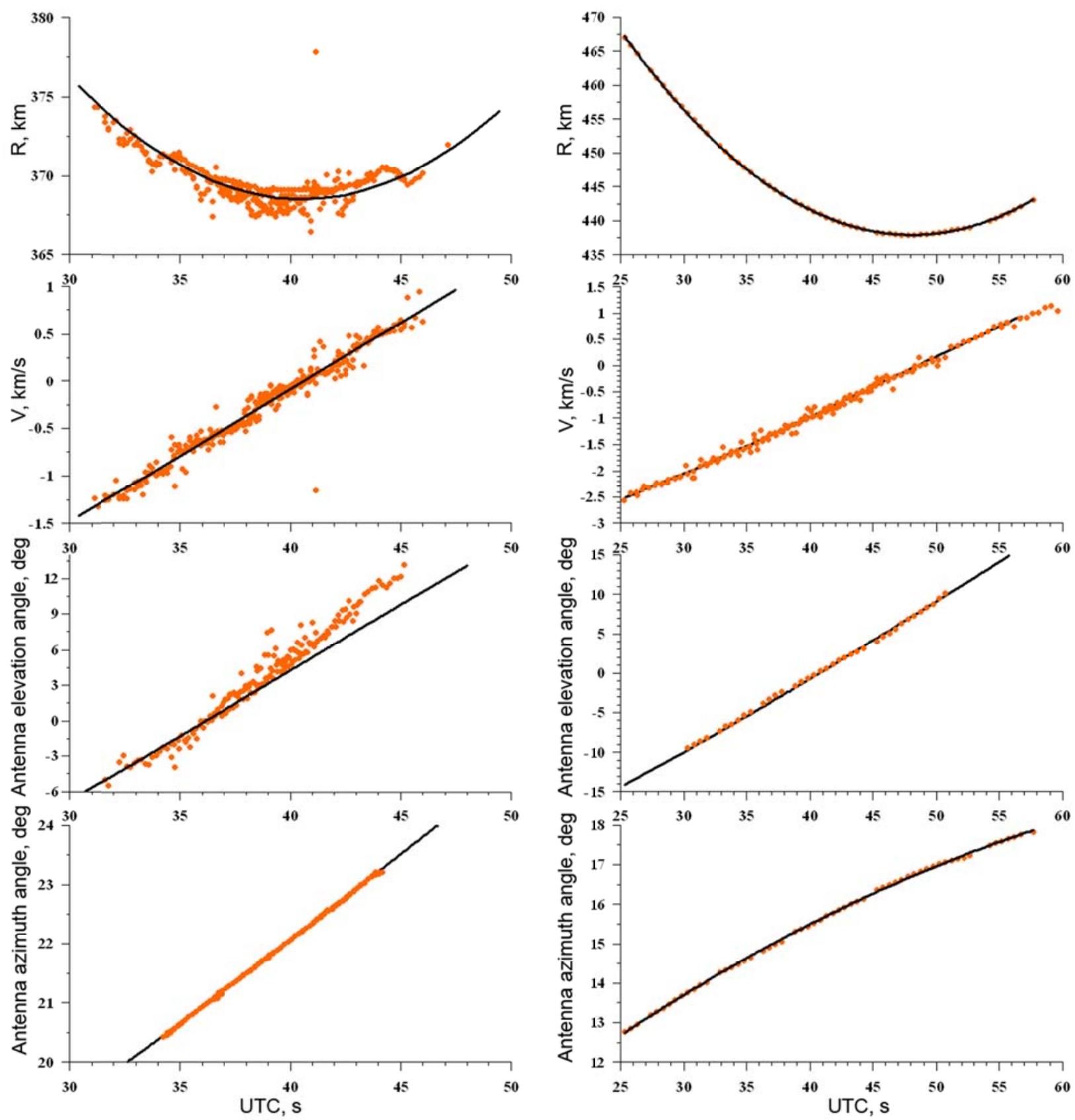

Figure 2. Measurements of Progress CS (from top to bottom): range $R$, speed $V$, antenna elevation angle, and azimuth for September 19, 2007 (left), July 26, 2014 (right). The orange color indicates measured data; the black color, calculated data

All the changes can be made in the CPLD firmware, and then it be downloaded at any time.

The interaction of MCU with DDS, GPS, and CPLD via serial interfaces allows us to use in the future any units of other manufacturing companies, without substantial upgrading of the entire IISR software. Only the microprogram for MCU will be modified.

Modern synthesizers in use allow us to reject one stage of multiplication in the subsystem for generating driving signals of transmitters and receiver local oscillators. In the previous version of such a subsystem, source DDS signals ( $\sim 20 \mathrm{MHz})$ were multiplied 8 times; in its current version, signals of the operating range 154-162 $\mathrm{MHz}$ are multiplied 4 times, thus significantly increas- ing the quality of generated radio signals.

The control channel of the entire synchronization system, implemented using the standard Ethernet equipment, excludes the need for any special interfaces and computers. We can use any computers with any operating systems to control the entire IISR hardware and software system.

Since 2014, all SEs with IISR have been carried out using the new synchronization and control system and the new digital receiver. Figure 2 shows the differences between obtained path parameters of the Progress CS in two sessions of the Radar-Progress SE: before the DCAS modernization (September 19, 2007, left panel) and after it (July 26, 2014, right panel). 
After the modernization, it became possible to use chirp signals, which can significantly improve the accuracy of range and angle measurements: with a signal-tonoise ratio of 10 , the range accuracy is $100-300 \mathrm{~m}$, the angle accuracy is $1-5$ arcmin. By comparison, the accuracy of measurements in the experiments until 2010 at the same signal-to-noise ratio was $1.5 \mathrm{~km}$ in range and 30-60 arcmin in angles. At present, the modernized DCAS identifies path parameters in real time, whereas before the modernization the processing took a long time and had several stages. The achieved accuracy in measuring path parameters in real time enabled us to solve the problem of pointing the telescope, installed in the Sayan Solar Observatory of ISTP SB RAS, at loworbit spacecraft, using IISR data.

\section{CONCLUSION}

The modernization of IISR's digital control and acquisition system during the Plasma-Progress and RadarProgress space experiments made from 2007 to 2015 has improved the accuracy of identification of path parameters of low-orbit spacecraft and has expanded the capabilities of this system for future measurements. The use of the modern hardware components led to the unification of all DCAS units and opened prospects for further modernization of IISR, unique instrument of national significance No. 01-28 included into the worldwide network of radars of this type.

Other results of the Plasma-Progress and RadarProgress SE, obtained with IISR, are reported in [Lebedev et al., 2011; Khakhinov et al., 2012; Borisov et al., 2012; Khakhinov et al., 2012; Korsun et al., 2014].

\section{REFERENCES}

Alsatkin S.S., Medvedev A.V., Ratovsky K.G. Some peculiarities in the ionosphere dynamics near the ionization maximum from Irkutsk Incoherent Scatter Radar data for low and moderate solar activities. Solnechno-zemnaya fizika [Solar-Terr. Phys.]. 2015, vol. 1, no. 3, pp. 28-36. (In Russian). DOI: $10.12737 / 11450$

Borisov B.S., Gabdullin F.F., Garkusha V.I., Korsun A.G., Kurshakov M.Yu., Strashinskiy V.A., Tverdokhlebova E.M., Khakhinov V.V. Radiophysical characteristics of low-orbit spacecraft plasma environment revealed by space experiments. Nelineinyi mir [Nonlinear World]. 2012, vol. 10, no. 10. pp. 700-709. (In Russian).

Khakhinov V.V., Potekhin A.P., Lebedev V.P., Alsatkin S.S., Ratovsky K.G., Kushnarev D.S., Tverdokhlebova E.M., Kurshakov M.Yu., Manzheley A.I., Timofeeva N.I. Results of remote sounding of ionospheric disturbances in active space experiments "Radar-Progress". Sovremennye problemy distantsionnogo zondirovaniya Zemli iz kosmosa [Modern problems of the Earth remote sounding from the space]. 2012, vol. 9, no. 3, pp. 199-208. (In Russian).

Khakhinov V.V., Potekhin A.P., Lebedev V.P., Kushnarev D.S., Alsatkin S.S. Some results of the active space experiments "Plasma-Progress" and "Radar-Progress". Vestnik Sibirskogo gosudarstvennogo aerokosmicheskogo universiteta imeni akademika M.F. Reshetneva [Bulletin of M.F. Reshetnev Siberian State Aerospace University]. 2013, Special Iss. 5 (51), pp. 160-163. (In Russian).

Khakhinov V.V., Shpynev B.G., Lebedev V.P., Kushnarev D.S., Alsatkin S.S., Khabituev D.S. Radiosounding of ionospheric disturbances generated by exhaust streams of the transport spacecraft "Progress" engines. Proc. PIERS, Moscow, Russia. 2012. P. 1168-1171.

Korsun A.G., Kurshakov M.Yu., Kushnarev D.S., Lebedev V.P., Tverdokhlebova E.M., Khakhinov V.V., Ratovsky K.G. Investigation into effect of spacecraft engines on the ionosphere. Nauchnoe obozrenie [Scientific Review]. 2014, vol. 8, no. 2, pp. 563-571. (In Russian).

Lebedev V.P., Khakhinov V.V., Gabdullin F.F., Korsun A.G., Tverdokhlebova E.M., Laletina E.A., Manzhaley A.I. Studying the characteristics of the plasma environment at low-orbiting space vehicles by radar methods. Cosmonautics and Rocket Engineering. 2008, vol. 50 (1). pp. 51-60.

Lebedev V.P., Khakhinov V.V., Kushnarev D.S., Tverdokhlebova E.M. Improving the efficiency of radar measurements made with Irkutsk Incoherent Scatter Radar. XXVIII Vserossiiskogo simposiuma "Radiolokatsionnoe issledovanie prirodnykh sred": Trudy [Proc. XXVIII National Symposium "Radar Study of Natural Environments"]. St. Petersburg, Russia. 2013, vol. 1, no. 10, pp. 324-331. (In Russian).

Lebedev V., Khakhinov V., Potekhin A., Kushnarev D., Zarudnev V. Variations of the Transport Spacecraft "Progress" Radar Characteristics Connected with the Orbital Maneuvering Subsystem Run. Proc. XXX URSI General Assembly, HP2.16. Istanbul, Turkey. 2011.

Potekhin A.P., Khakhinov V.V., Medvedev A.V., Kushnarev D.S., Lebedev V.P., Shpynev B.G. Active space experiments with the use of the transport spacecraft "Progress" and Irkutsk IS Radar. Proc. PIERS. Moscow, Russia. August 1821, 2009. Moscow, Russia. 2009. P. 217-221

Potekhin A.P., Medvedev A.V., Zavorin A.V., Kushnarev D.S., Lebedev V.P., Shpynev B.G. Development of diagnostic capabilities of the Irkutsk incoherent scattering radar. Kosmicheskie issledovaniya [Cosmic Research]. 2008, vol. 46, no. 4, pp. 356-362. DOI: $10.1134 / \mathrm{S} 0010952508040102$.

Shcherbakov A.A., Medvedev A.V., Kushnarev D.S., Tolstikov M.V., Alsatkin S.S. Calculation of meridional neutral winds in the middle latitudes from the Irkutsk incoherent scatter radar. J. Geophys. Res.: Space Phys. 2015, vol. 120, no. 12 , pp. 10851-10863. DOI: 10.1002/2015JA021678.

Zherebtsov G.A., Zavorin A.V., Medvedev A.V., Nosov V.E., Potekhin A.P., Shpynev B.G. Irkutsk Incoherent Scatter Radar. Radiotekhnika i electronica [J. Communication Technology and Electronics]. 2002, vol. 47, no. 11, pp. 1339-1345. (In Russian).

URL: http://www.energia.ru/rus/iss//researches/geophis13.html (accessed May 18, 2017).

URL: http://knts.tsniimash.ru/ru/site/Experiment_q.aspx? $\mathrm{idE}=183$ (accessed May 18, 2017).

\section{How to cite this article}

Kushnarev D.S., Lebedev V.P., Khakhinov V.V., Evstifeev S.E., Zarudnev V.E. Modernization of the Irkutsk Incoherent Scatter Radar. SolarTerrestrial Physics. 2017. Vol. 3, iss. 3. P. 76-81. DOI: 10.12737/ stp-33201708 